\title{
Yeast adaptation to weak acids prevents futile energy expenditure
}

\author{
Azmat Ullah ${ }^{1,2}$, Gayathri Chandrasekaran ${ }^{1}$, Stanley Brul ${ }^{1}$ and Gertien J. Smits ${ }^{1 *}$ \\ Department of Molecular Biology and Microbial Food Safety, Swammerdam Institute for Life Sciences, Netherlands Institute for Systems Biology, \\ University of Amsterdam, Amsterdam, Netherlands \\ 2 Food Science Department, Government College University Faisalabad, Faisalabad, Pakistan
}

\section{Edited by:}

Nuno P. Mira, Instituto Superior

Técnico, Portugal

Reviewed by:

Peter W. Piper, University of

Sheffield, UK

Nuno P. Mira, Instituto Superior

Técnico, Portugal

\section{*Correspondence:}

Gertien J. Smits, Department of

Molecular Biology and Microbial

Food Safety, Swammerdam Institute

for Life Sciences, Netherlands

Institute for Systems Biology,

University of Amsterdam, Science

Park 904, 1098 XH Amsterdam,

Netherlands

e-mail:g.j.smits@uva.nl
Weak organic acids (WOAs) are widely used preservatives to prevent fungal spoilage of foods and beverages. Exposure of baker's yeast Saccharomyces cerevisiae to WOA leads to cellular acidification and anion accumulation. Pre-adaptation of cultures reduced the rate of acidification caused by weak acid exposure, most likely as a result of changes in plasma membrane or cell wall composition. In order to adapt to sublethal concentrations of the acids and grow, yeast cells activate ATP consuming membrane transporters to remove protons and anions. We explored to what extent ATP depletion contributes to growth inhibition in sorbic or acetic acid treated cells. Therefore, we analyzed the effect of the reduction of proton and anion pumping activity on intracellular $\mathrm{pH}\left(\mathrm{pH}_{\mathrm{i}}\right)$, growth, and energy status upon exposure to the hydrophilic acetic acid (HA) and the lipophilic sorbic acid (HS). ATP concentrations were dependent on the severity of the stress. Unexpectedly, we observed a stronger reduction of ATP with growth reducing than with growth inhibitory concentrations of both acids. We deduce that the not the ATP reduction caused by proton pumping, but rather the cost of sorbate anion pumping contributes to growth inhibition. A reduction of proton pumping activity may reduce ATP consumption, but the resulting decrease of $\mathrm{pH}_{\mathrm{i}}$ affects growth more. ATP utilization was differentially regulated during moderate and severe stress conditions. We propose that the energy depletion alone is not the cause of growth inhibition during HA or HS stress. Rather, the cells appear to reduce ATP consumption in high stress conditions, likely to prevent futile cycling and maintain energy reserves for growth resumption in more favorable conditions. The mechanism for such decision making remains to be established.

Keywords: weak organic acid stress, food preservatives, intracellular $\mathrm{pH}$, spoilage yeast, Saccharomyces cerevisiae, bioenergetics, plasma membrane pumps

\section{INTRODUCTION}

Every year, large quantities of food are contaminated by microbes and become unfit for human consumption. Food spoilage microbes in large-scale food industries is prevented among other methods with weak organic acids (WOAs) such as sorbic, acetic, benzoic, and propionic acid, which are considered to be safe for human consumption. In aqueous solution, WOAs exist in $\mathrm{pH}-$ dependent equilibrium between uncharged acidic molecules and their charged anions. The protonated, uncharged molecule that is abundant at low $\mathrm{pH}$ can freely permeate the plasma membrane. Upon encountering the high $\mathrm{pH}(\sim 7)$ inside the cell the acid dissociates to form a charged proton and anion which diffuse over the membrane anymore (Brul and Coote, 1999; Lambert and Stratford, 1999; Orij et al., 2009). Diffusion of weak acids into the cell could theoretically continue until equilibrium is reached between the concentration of the protonated state inside and outside the cell.

A first consequence of WOA stress is cellular acidification [reviewed in Piper et al. (2001), Orij et al., 2011]. Intracellular $\mathrm{pH}\left(\mathrm{pH}_{\mathrm{i}}\right)$ affects many cellular processes, and even a slight deviation of $\mathrm{pH}_{\mathrm{i}}$ already affects intracellular metabolic reactions, as it influences the ionization states of acidic and basic side chains of amino acids and thereby protein activity (Orij et al., 2011). $\mathrm{pH}_{\mathrm{i}}$ is also a critical component of the total electro-chemical gradient which is responsible for the transport of molecules across membranes (Orij et al., 2011). The release of protons and subsequent cytoplasmic acidification leads to inhibition of essential metabolic functions (Krebs et al., 1983; Bracey et al., 1998), inhibition of glycolysis (Pearce et al., 2001) and therefore reduction of the cell's ability to generate ATP. In addition, the cellular activities counteracting acidification and anion accumulation consume ATP (Piper et al., 1998; Holyoak et al., 1999). In yeast intracellular acidification is partly counteracted by the activity of Pmalp, a plasma membrane $\mathrm{H}^{+}$-ATPase pump. PMA1 is an essential gene that encodes the major $\mathrm{pH}_{\mathrm{i}}$ regulator in baker's yeast (Serrano et al., 1986). It pumps $\mathrm{H}^{+}$ions out of the cell using ATP hydrolysis at a 1:1 ratio (de Kok et al., 2012). This activity consumes about $20 \%$ of the ATP produced during normal conditions (Morsomme et al., 2000) and up to 60\% during weak acid stress (Holyoak et al., 1996). Lipophilic WOA stress also induces the plasma membrane ATP-binding cassette $(\mathrm{ABC})$ transporter Pdr12p (Hatzixanthis et al., 2003), which is believed to play a role in the adaptation of Saccharomyces cerevisiae to these weak acids by pumping out anions (Holyoak et al., 1999) at the cost of energy, either 
ATP or an aspect of membrane potential, possibly the proton gradient (Breeuwer et al., 1994; Henriques et al., 1997). PDR12 was shown to be important for the adaptation of yeast cells to grow in the presence of lipophilic weak acid preservatives, and pdr12 $\Delta$ mutants are hypersensitive to lipophilic acids at low $\mathrm{pH}$ (Holyoak et al., 1999; Hatzixanthis et al., 2003). The deletion mutant is however not sensitive to highly lipophilic, long-chain fatty acids alcohols and dicarboxylic acids (Hatzixanthis et al., 2003), and induction of the protein is not sufficient for growth in the presence of sorbic acid (Papadimitriou et al., 2007).

Once outside, the protons and anions exported from the cell will re-associate due to the low medium $\mathrm{pH}$, and can diffuse back over the membrane. This constitutes a futile cycle that will provide a constant drain of the cell's energy reserves. Non-futile ATP consumption should lead to decreased diffusional entry of acid, and a decrease of pumping activity might lead to a reduced ATP burden (Cole and Keenan, 1986; Piper et al., 2001; Mira et al., 2010b). Indeed, several genome-wide analyses of the effects of WOA stress on yeast have revealed that the energy burden is significant, and that this might be a major cause of the growth inhibitory effect (Mollapour et al., 2004; Schüller et al., 2004; Mira et al., 2010a), and the effects of weak acids on yeast growth are observed as a linear relation between WOA concentration and maintenance energy requirement (Quintas et al., 2005). In this study we aimed to determine whether the accumulation of protons and anions in the cell, or rather the depletion of ATP caused by the export of both is the cause of the growth inhibitory effect of these acids.

\section{MATERIALS AND METHODS

YEAST STRAINS AND PLASMIDS

S. cerevisiae BY4741 (MATa his $3 \Delta 1$ leu $2 \Delta 0$ met $15 \Delta 0$ ura $3 \Delta 0$ ) and the derivatives pma1-007 (YGL007W::kanMX4) and $p d r 12 \Delta$ (YPL058C::kanMX4) were used in this study (EUROSCARF, Germany). All strains were transformed with plasmid pYES-ACTpHluorin to measure $\mathrm{pH}_{\mathrm{i}}$ as described earlier (Ullah et al., 2012). All chemicals were purchased from Sigma-Aldrich (Germany), unless otherwise indicated.

\section{GROWTH CONDITIONS}

Cells were grown at $30^{\circ} \mathrm{C}$ in a defined mineral media medium according to (Verduyn et al., 1992) using 2\% glucose. Pre-inocula were grown overnight in Erlenmeyer flasks shaking at $200 \mathrm{rpm}$ in the same media as above, buffered at $\mathrm{pH} 5.0$ with $25 \mathrm{mM}$ potassium citrate. Strains were cultivated in $500 \mathrm{ml}$ batch fermenters to an initial $\mathrm{OD}_{600}$ of 0.1 , with a steady airflow $(500 \mathrm{ml} / \mathrm{min})$ and stirring rate $(600 \mathrm{rpm})$. External $\mathrm{pH}$ was maintained at 5.0 by titration with 0.2 M KOH using Applikon ADI 1030 Controller (Applikon, Schiedam, the Netherlands). Cultures were exposed to WOA in early exponential phase $\left(\mathrm{OD}_{600} \sim 1.0\right)$ as indicated.

\section{MEASUREMENT OF OD $_{600}$ AND $\mathrm{pH}_{\mathrm{i}}$}

$\mathrm{pH}_{\mathrm{i}}$ was measured as described before (Orij et al., 2009). Growth $\left(\mathrm{OD}_{600}\right)$ and $\mathrm{pH}_{\mathrm{i}}$ were monitored at regular intervals for $4 \mathrm{~h}$. Culture samples from the batch fermenters were transferred to CELLSTAR black polystyrene clear bottom 96-well microtiter plates (BMG Labtechnologies, Germany). $\mathrm{OD}_{600}$ and $\mathrm{pH}_{\mathrm{i}}$ of the cultures were measured in a FLUOstar Optima microtiter plate reader (BMG Labtechnologies, Germany) in three technical replicates.

\section{DETERMINATION OF ACIDIFICATION RATE}

Growing cultures of $S$. cerevisiae were exposed to HA ( $45 \mathrm{mM})$ and $\mathrm{HS}(1 \mathrm{mM})$, or control conditions at $\mathrm{pH} 5.0$ and $30^{\circ} \mathrm{C}$ for $4 \mathrm{~h}$. Cells were harvested by centrifugation at $5000 \mathrm{rpm}$ for $5 \mathrm{~min}$, washed, and suspended in fresh medium (with or without glucose). Pre-exposed cultures were pulsed with WOA and $\mathrm{pH}_{\mathrm{i}}$ was monitored at one-second intervals.

\section{NUCLEOTIDE EXTRACTION}

Samples for extraction of metabolites were collected at $t=0$, $0.5,1,2,4 \mathrm{~h}$ after exposure of cultures to WOAs. Metabolites were extracted with boiling ethanol after quenching in methanol (Gonzalez et al., 1997). Briefly, pre-weighed cell culture samples $(20 \mathrm{ml})$ were quenched using $60 \%(\mathrm{v} / \mathrm{v})$ ice cold aqueous methanol $(60 \mathrm{ml})$. Samples were centrifuged at $5000 \mathrm{~g}$ for $5 \mathrm{~min}$ at $-20^{\circ} \mathrm{C}$. Boiling ethanol $75 \%(\mathrm{v} / \mathrm{v})$ was added to the pellet and incubated for $3 \mathrm{~min}$ at RT. After centrifugation for $5 \mathrm{~min}$ at $-10^{\circ} \mathrm{C}$ the supernatant was transferred to eppendorf tubes. The liquid was evaporated using a Speed-Vac, the residue was reconstituted in $180 \mu \mathrm{l}$ of demi water, and stored at $-80^{\circ} \mathrm{C}$ until further analysis.

\section{NUCLEOTIDE QUANTIFICATION}

Metabolite measurements were performed by fluorimetric detection of NADH/NADPH using appropriate coupling enzymes (Gonzalez et al., 1997). Emission was measured at $460 \mathrm{~nm}$ after excitation at $340 \mathrm{~nm}$ using a FLUOstar Optima microtiter plate reader (BMG Labtechnologies, Germany).

Enzymatic determination of ATP was done at $30^{\circ} \mathrm{C}$ in TEA buffer $(66 \mathrm{mM}, \mathrm{pH} 7.6)$ containing $6.6 \mathrm{mM} \mathrm{MgSO}_{4}$ and $0.65 \mathrm{mM}$ $\mathrm{NADP}^{+}$. ATP was consumed by hexokinase $(1.9 \mathrm{U} / \mathrm{ml})$ in reaction with glucose $(0.1 \mathrm{mM})$. The reaction reached an end point after $10 \mathrm{~min}$, and NADH concentrations were determined.

$\mathrm{ADP}$ was also determined at $30^{\circ} \mathrm{C}$ in the buffer containing $66 \mathrm{mM}$ TEA-pH 7.6, $6.6 \mathrm{mM} \mathrm{MgSO}_{4}, 66 \mathrm{mM} \mathrm{KCl}, 0.2 \mathrm{mM}$ $\mathrm{NADH}$, and lactate dehydrogenase $(1.8 \mathrm{U} / \mathrm{ml})$. This step eliminates pyruvate and converts it into lactate, after completion of the reaction $0.2 \mathrm{mM}$ phosphoenolpyruvate and pyruvate kinase $(1.8 \mathrm{U} / \mathrm{ml})$ was added to measure the levels of ADP. The end point of this reaction was found to be $40 \mathrm{~min}$ after enzyme addition. The concentration of ATP and ADP was expressed in $\mu \mathrm{mol} / 3 \times 10^{7}$ cells $/ \mathrm{ml}$ assuming the number of cells at $\mathrm{OD}_{600} 1$ was $\sim 3 \times 10^{7}$ cells (Orij et al., 2009). The recovery of the ATP after extraction was $90.75 \%$ and this represents the efficiency and stability of the metabolite during this extraction procedure (Table 1).

\section{RESULTS \\ ADAPTATION TO WEAK ACIDS INCREASES PASSIVE DEFENSE MECHANISMS}

$S$. cerevisiae acquires resistance to WOAs by activating the membrane $\mathrm{H}^{+}$-ATPase Pmalp and transporters to expel anions. Both 
processes cost energy. Baker's yeast does not degrade or metabolize the WOAs in the presence of glucose (Mollapour et al., 2008), so this energy dependent extrusion will be futile unless cells restrict the diffusional entry of WOA or increase the cellular capacity for absorption of the stress, for instance by increasing the concentration of buffering metabolites. Therefore, we probed the cells' ability to restrict the diffusional entry of weak acids. We have used two different WOAs, sorbic acid and acetic acid. Both acids have different toxic effect despite their identical $\mathrm{pK}_{\mathrm{a}}$ values. HA inhibits growth because of its effect on cytosolic $\mathrm{pH}$, whereas HS affects growth mostly by anion specific inhibitory effects (Ullah et al., 2012). We pulsed HA and HS to growing cultures of $S$. cerevisiae and estimated the initial entry by determination of the rate of intracellular acidification (Figures 1A,C). We confirmed that HS acidified cells faster than HA. Next, we pre-exposed the cultures to $45 \mathrm{mM}$ of acetic acid or $1 \mathrm{mM}$ sorbic acid, both of which inhibit growth by $\sim 50 \%$, to induce the

Table 1 | Metabolite recovery after extraction in boiling ethanol coupled with $60 \%$ methanol quenching.

\begin{tabular}{llrll}
\hline Sample & $\begin{array}{l}\text { Exogenous ATP } \\
\text { added }\end{array}$ & Measured ATP & Difference & Recovery \\
\hline 1 & 0 & $8.40 \pm 0.40$ & - & - \\
2 & 5 & $12.00 \pm 0.80$ & $3.60 \pm 1.02$ & $72 \pm 20 \%$ \\
3 & 7.60 & $14.40 \pm 0.36$ & $6.00 \pm 0.30$ & $78 \pm 4 \%$ \\
4 & 10 & $17.20 \pm 1.18$ & $8.80 \pm 1.50$ & $88 \pm 15 \%$ \\
\hline
\end{tabular}

adaptive response. After $4 \mathrm{~h}$ of incubation, when the $\mathrm{pH}_{\mathrm{i}}$ recovery is maximal [back to $\sim 6.5$ in both cases, see Ullah et al. (2012)], cells were washed, suspended into fresh media and pulsed with $20 \mathrm{mM}$ and $45 \mathrm{mM}$ of HA or 1 or $1.2 \mathrm{mM}$ of HS (Figure 1). We show only the results from the $20 \mathrm{mM}$ HA pulse, as $45 \mathrm{mM}$ in the absence of glucose resulted in $\mathrm{pH}_{\mathrm{i}}$ values that were outside of the range of the calibration curve (our unpublished data). The reduction of acidification rate by the pre-exposure was, however, similar. The rate of acidification was reduced by $50 \%$, and pre-exposure to both acids caused the cells to have a higher $\mathrm{pH}_{\mathrm{i}} 1 \mathrm{~min}$ after an acid pulse. For $\mathrm{HS}$, the results with $1 \mathrm{mM}$ or $1.2 \mathrm{mM}$ were similar (our unpublished data), but the reduction in entry rate was more apparent in case of the $1.2 \mathrm{mM}$ pulse.

A reduction of the rate of acidification can be accomplished in two ways: Membranes can be altered to reduce the entry of the acids (Mira et al., 2010a), or the induction of (proton) pumping activity balancing the entry also reduces acidification (Ullah et al., 2012). To distinguish between these options, we compared the acidification of pre-exposed and control cultures of $S$. cerevisiae wild-type in the presence and absence of glucose. Removal of glucose from medium leads to the depletion of the ATP pool within minutes (Ashe et al., 2000; Thomsson et al., 2005), and thereby disables the pumping activity. Any differences in initial acidification upon WOA pulses under these circumstances should be caused by changes in influx. Although in the absence of glucose $\mathrm{pH}_{\mathrm{i}}$ was reduced more strongly than in the presence of a source of energy, the rate of acidification was virtually identical in both situations (Figure 1). In contrast, the effect of the adaptive response

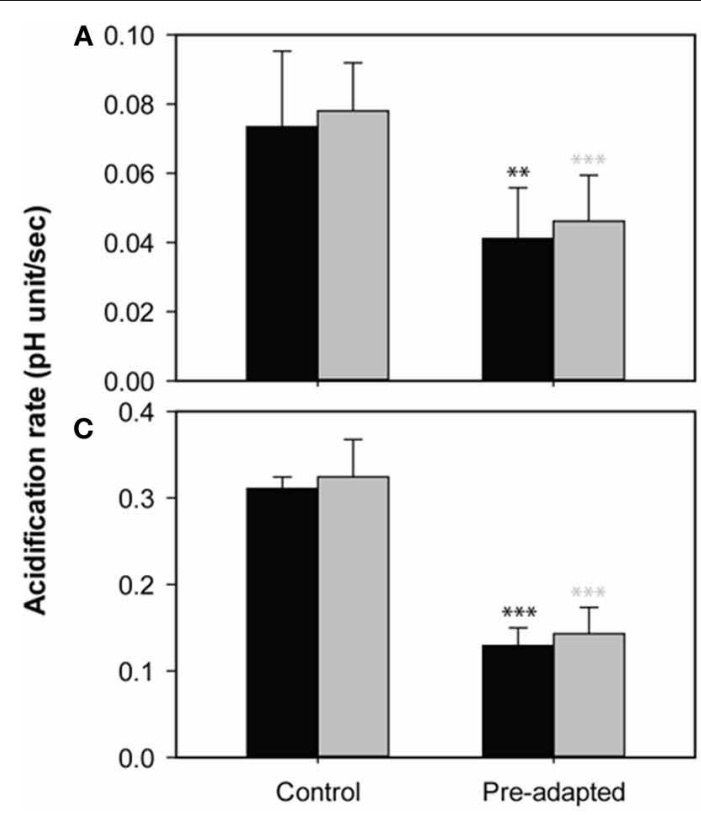

FIGURE 1 | Effect of WOA pre-exposure on acid entry. The rate of acidification (A,C) and $\mathrm{pHi}$ reduction after $1 \mathrm{~min}(\mathbf{B}, \mathbf{D})$ caused by $20 \mathrm{mM}$ acetic acid $(\mathbf{A}, \mathbf{B})$ or $1.2 \mathrm{mM}$ sorbic acid $\mathbf{( C , D )}$, in control cultures (no pre-exposure) and culture pre-exposed to $45 \mathrm{mM}$ of $\mathrm{HA}(\mathbf{A}, \mathbf{B})$ or $1 \mathrm{mM}$ of $\mathrm{HS}$ (C,D). The same experiment was performed in the presence (black) and

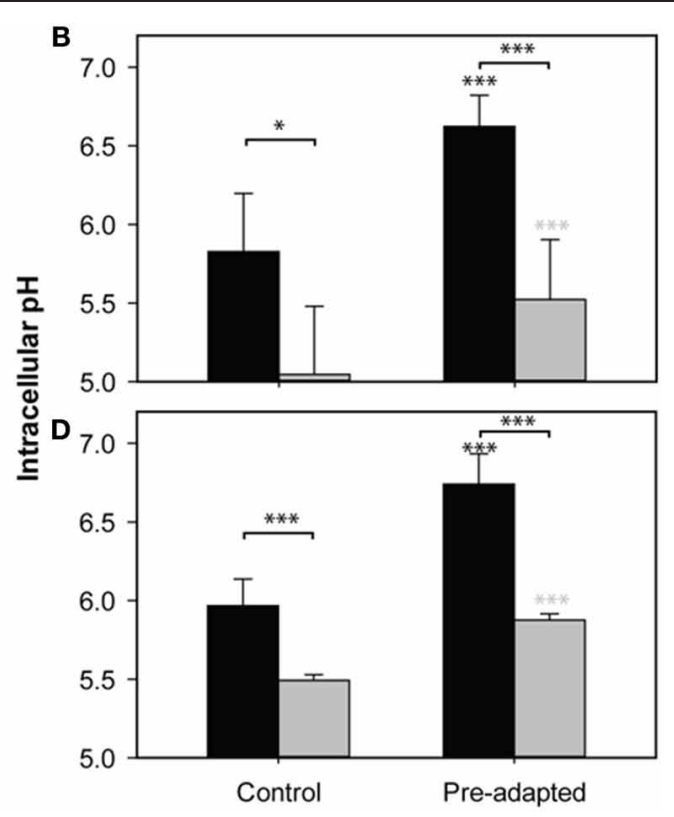

absence (gray) of glucose. Data presented are the average of three independent cultivations and error bars represent standard deviations. An asterisk indicates significance of the difference between control and pre-adapted cultures, or between conditions indicated with a marker (two-tailed $t$-test; $* p<0.05 ; * * p<0.01 ;{ }^{* * *} p<0.001$ ). 
to WOAs induced by pre-exposure caused a decrease in the rate of acidification, which was again identical with or without glucose. This decrease in acidification rate is therefore not dependent on ATP dependent processes, and must be caused by a decreased diffusional entry of WOAs by remodeling of the cell surface. It should be noted that while the absence of an energy source did not affect the acidification rate, the $\mathrm{pH}_{\mathrm{i}}$ reached after $1 \mathrm{~min}$ was lower in cultures without glucose (Figures 1B,D). Therefore, while the initial acidification rate, reflecting diffusional entry, is reduced by the pre-adaptation, adapted cells could not completely overcome the diffusional entry, and still need energy for the maintenance of $\mathrm{pH}_{\mathrm{i}}$ in the presence of WOA. This energy demand might result in depletion of cellular ATP and therefore in reduced growth.

\section{WOAs LEAD TO ATP DEPLETION AT LOW DOSAGES}

To test whether the ATP consumption for counteracting acid stress is a major cause of growth inhibition by weak acids we measured the intracellular concentrations of adenine nucleotides (ATP, ADP), and simultaneously monitored growth and $\mathrm{pH}_{\mathrm{i}}$ upon acid exposure. We exposed S. cerevisiae wild-type to concentrations of HS and HA that inhibited growth by 50 and $100 \%$ in our previous work. For acetic acid this corresponded to $40 \mathrm{mM}$ and $70 \mathrm{mM}$, while for HS $1 \mathrm{mM}$ and $2 \mathrm{mM}$ were used. Growth and $\mathrm{pH}_{\mathrm{i}}$ profiles are shown in Figure 2. Addition of WOA caused immediate acidification (Figure 2B). With $40 \mathrm{mM}$ of HA, recovery started instantaneously, and $\mathrm{pH}_{\mathrm{i}}$ was restored almost to the $\mathrm{pH}_{\mathrm{i}}$ of unstressed cell after $80 \mathrm{~min}$ (Figure 2B). However, no $\mathrm{pH}_{\mathrm{i}}$ recovery was observed with $70 \mathrm{mM}$ HA stress in the time frame studied, and growth was not resumed (Figures 2A,B). Cellular ATP was depleted by $60 \%$ in $40 \mathrm{mM}$ HA stressed cells. Remarkably, $70 \mathrm{mM}$ caused only a $21 \%$ reduction (Figure 2C). $\mathrm{ADP}$ was also reduced in both conditions, but again more at moderate than at severe stress (Figure 2D).

The HS concentrations used in these conditions did not recapitulate the 60 and $90 \%$ growth inhibition observed in our previous work (Orij et al., 2009; Ullah et al., 2012), possibly due to a different experimental setup. Growth inhibition and acidification were slightly higher with $2 \mathrm{mM}$ than with $1 \mathrm{mM}$ HS stress. We did not observe recovery of either $\mathrm{pH}_{\mathrm{i}}$ or growth within the time frame (Figures 2E,F).

With $1 \mathrm{mM}$ HS, ATP levels decreased by $\sim 51 \%$ at $t=0.5 \mathrm{~h}$ and did not recover till $t=4 \mathrm{~h}$. Decrease of ATP after $2 \mathrm{mM}$ HS stress was less than after $1 \mathrm{mM}$ HS (Figure 2G). The ADP concentrations were decreased by moderate stress conditions, while no significant decrease was observed at the higher dosage.

\section{REDUCED ATP CONSUMPTION BY PROTON PUMPING DOES NOT IMPROVE GROWTH}

We hypothesized that if ATP depletion is a stronger cause of growth inhibition than the accumulation of protons or anions itself, decreasing the pumping activity might actually improve growth. Since PMA1 is an essential gene, we used the pma1 hypomorph pma1-007 (Porat et al., 2005), which has only 50\% Pmalp expression and activity, to assess the effect of reduction of proton pumping associated ATP consumption on the growth inhibitory effect of sorbic and acetic acid.
Cells with reduced Pmalp activity did not show hypersensitivity to HS compared to wild-type (Figure $3 E$ ), and $\mathrm{pH}_{\mathrm{i}}$ reduction and recovery were similar, consistent with our previous experiments (Ullah et al., 2012). Growth recovery of pma1-007 coincided with $\mathrm{pH}_{\mathrm{i}}$ restoration during HS stress. The ATP concentration initially decreased less than in wild-type, with only $28 \%$ for $1 \mathrm{mM}$, compared to $51 \%$ in wild-type. Upon $1 \mathrm{mM}$ HS stress, it did however continue to decrease over the course of time. Two millimolar HS stress resulted in an ATP depletion similar to the wild-type (Figure 3G). In both stress conditions ADP levels were significantly reduced by the addition of the acid (Figure $\mathbf{3 H}$ ). However, the reduced ATP consumption did not lead to an alleviation of the growth inhibition, suggesting that the proton extrusion coupled ATP consumption is less of a cause of growth inhibition than is the acidification itself.

We have shown previously that for HA, acidification correlates strongly with growth inhibition, and the effect of HA on growth and $\mathrm{pH}_{\mathrm{i}}$ was enhanced by decreasing Pmalp activity (Ullah et al., 2012). Indeed, the mutant pma1-007 was more sensitive to HA. Even moderate stress $(40 \mathrm{mM})$ had a severe effect on growth of the mutant compared to wild-type (Figure 3). Therefore, to still assess the effect of a 50\% growth inhibitory concentration, we included a $25 \mathrm{mM}$ HA stress condition. Thus, three concentrations $(25,40$, and $70 \mathrm{mM})$ of acetic acid stress were added to growing cultures of pma1-007 cells. The $\mathrm{pH}_{\mathrm{i}}$ of pma1-007 dropped below $\mathrm{pH} 5.0$ with all three concentrations, and growth and $\mathrm{pH}_{\mathrm{i}}$ could be restored after the $25 \mathrm{mM}$ HA stress only (Figures 3A,B). As observed with wild-type, the lower concentration of HA ( $25 \mathrm{mM})$ caused a strong depletion of ATP, while the higher concentrations (40 and $70 \mathrm{mM}$ ) actually led to a smaller reduction of ATP (Figure 3C).

Interestingly, growth of pma1-007 was hardly affected by $25 \mathrm{mM}$ HA stress, but the drop in the cellular ATP was prominent and ATP remained low up to $4 \mathrm{~h}$ after the initial stress (Figure 3C). ADP concentrations were also decreased compared to control (Figure 3D). Therefore, reduction of Pmalp activity did not result in higher ATP concentrations upon stress, and did not alleviate the stress phenotype. Rather, it enhanced the effect of acetic acid stress because of insufficient proton extrusion capacity. It appears, therefore, that the ATP consumption by the proton pump does not contribute strongly to the growth inhibitory effect of these two weak acids, increased acidification does.

\section{ANION EXPULSION CONTRIBUTES STRONGLY TO ATP CONSUMPTION}

The role of $\operatorname{Pdr} 12 p$ under acetic acid stress remains illunderstood. Pdr12p is not required for HA resistance and its deletion has no effect on growth in the presence of HA (Bauer et al., 2003; Ullah et al., 2012). Since Pdr12p expression is not induced by $\mathrm{HA}$ and its activity is not required for the extrusion of anions or protons during HA stress, we predicted that deletion of the gene would not affect adenylate nucleotide concentrations upon acetic acid stress, but would do so in case of HS exposure. Indeed, upon acetic acid stress, the growth profile of $p d r 12 \Delta$ was similar to the wild-type 

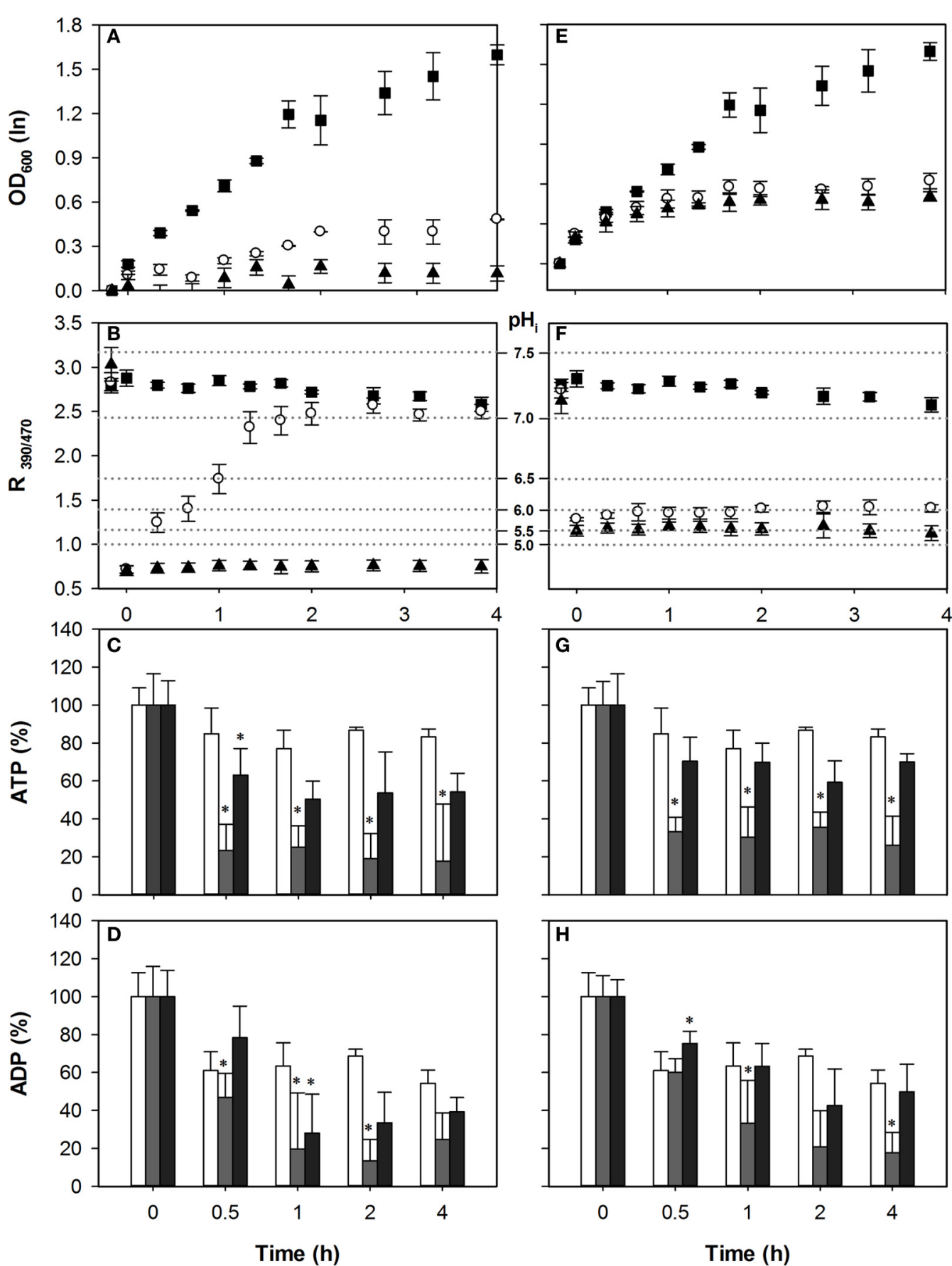

FIGURE 2 | Effect of acetic acid (left hand panels) and sorbic acid (right hand panels) on growth $(A, E)$, intracellular pH $(B, F), A T P$ (C,G), and ADP (D,H) levels of BY4741. Growing cultures were exposed to $0 \mathrm{mM}$ ( $\square$ and white bars), $40 \mathrm{mM} \mathrm{HA}$ or $1 \mathrm{mM} \mathrm{HS}$ (o and gray bars), and $70 \mathrm{mM} \mathrm{HA}$ or $2 \mathrm{mM} \mathrm{HS}$ ( $\mathbf{\Delta}$ and dark gray bars) at $t=0 . \mathrm{pH}_{\mathrm{i}}$ data are presented as ratio of fluorescence emission upon excitation at
$390 \mathrm{~nm}$ and $470 \mathrm{~nm}\left(\mathrm{R}_{390 / 470}\right)$ while the relevant $\mathrm{pH}_{\mathrm{i}}$ values derived from the calibration curves are also indicated. Data presented are the average of three independent cultivations and error bars represent standard deviation. An asterisk indicates significance of the difference between acid exposed and control cultures at the same time point (two-tailed t-test; $P<0.05)$.
(Figure 4A). Both concentrations led to a $\mathrm{pH}_{\mathrm{i}}$ decrease to below 5 , and as with wild-type $\mathrm{pH}_{\mathrm{i}}$ could be restored only in the $40 \mathrm{mM}$ HA stress condition (Figure 4B). The pattern of adenylate nucleotides observed in $p d r 12 \Delta$ was similar to that of wild-type,
(Figures 4C,D) corroborating the idea that Pdr12p activity does not contribute to ATP depletion in case of acetic acid stress. Cellular ADP concentrations were also reduced (Figure 4D) again more strongly at lower stress. 

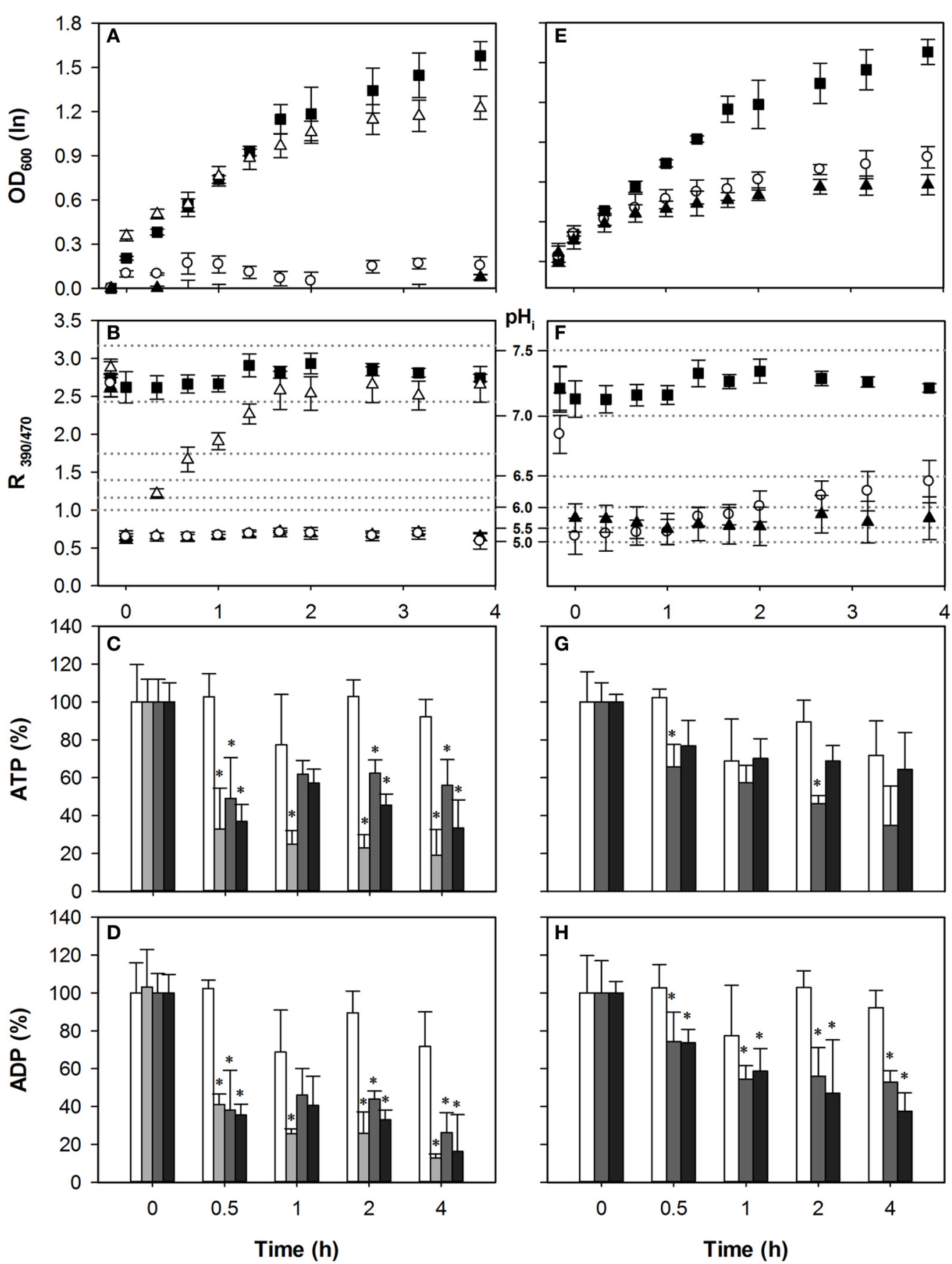

FIGURE 3 | Effect of acetic acid (left hand panels) and sorbic acid (right hand panels) on growth $(A, E)$, intracellular pH $(B, F)$, cellular ATP $(C, G)$, and ADP (D,H) concentrations of pma1-007. Growing cultures were exposed to $0 \mathrm{mM}$ ( $\square$ and white bars), $25 \mathrm{mM}$ ( $\triangle$ and light gray bars), $40 \mathrm{mM}$ HA or $1 \mathrm{mM} \mathrm{HS}$ (o and dark gray bars), and $70 \mathrm{mM} \mathrm{HA}$ or $2 \mathrm{mM} \mathrm{HS}$ ( $\Delta$ and black bars) of $\mathrm{HA} / \mathrm{HS}$ at $t=0 . \mathrm{pH}_{\mathrm{i}}$ data are presented as ratio of fluorescence emission upon excitation at $390 \mathrm{~nm}$ and $470 \mathrm{~nm}\left(\mathrm{R}_{390 / 470}\right)$ while the relevant $\mathrm{pH}_{\mathrm{i}}$ values derived from the calibration curves are also indicated. Data presented are the average of three independent cultivations and error bars represents standard deviation. An asterisk indicates significance of the difference between acid exposed and control cultures at similar time point (two-tailed t-test; $P<0.05$ ). $40 \mathrm{mM} \mathrm{HA}$ or $1 \mathrm{mM} \mathrm{HS}$.
Pdr12p expression is induced by sorbate and benzoate after 60-90 min of acid exposure to levels almost as high as Pmalp (Piper et al., 1998; Papadimitriou et al., 2007). The $\mathrm{pH}_{\mathrm{i}}$ of pdr12 $\Delta$ cultures decreased to 6.5 and 6.0 upon exposure to $1 \mathrm{mM}$ and $2 \mathrm{mM}$ of HS, respectively (Figure $4 \mathbf{F}$ ). Upon exposure to $1 \mathrm{mM} \mathrm{HS}, p d r 12 \Delta$ cells recovered growth after $4 \mathrm{~h}$ of adaptation (Figure 4E). However, cells treated with $2 \mathrm{mM}$ HS did not recover growth and $\mathrm{pH}_{\mathrm{i}}$, in line with our previous analysis. If $\mathrm{Pdr} 12 \mathrm{p}$ 

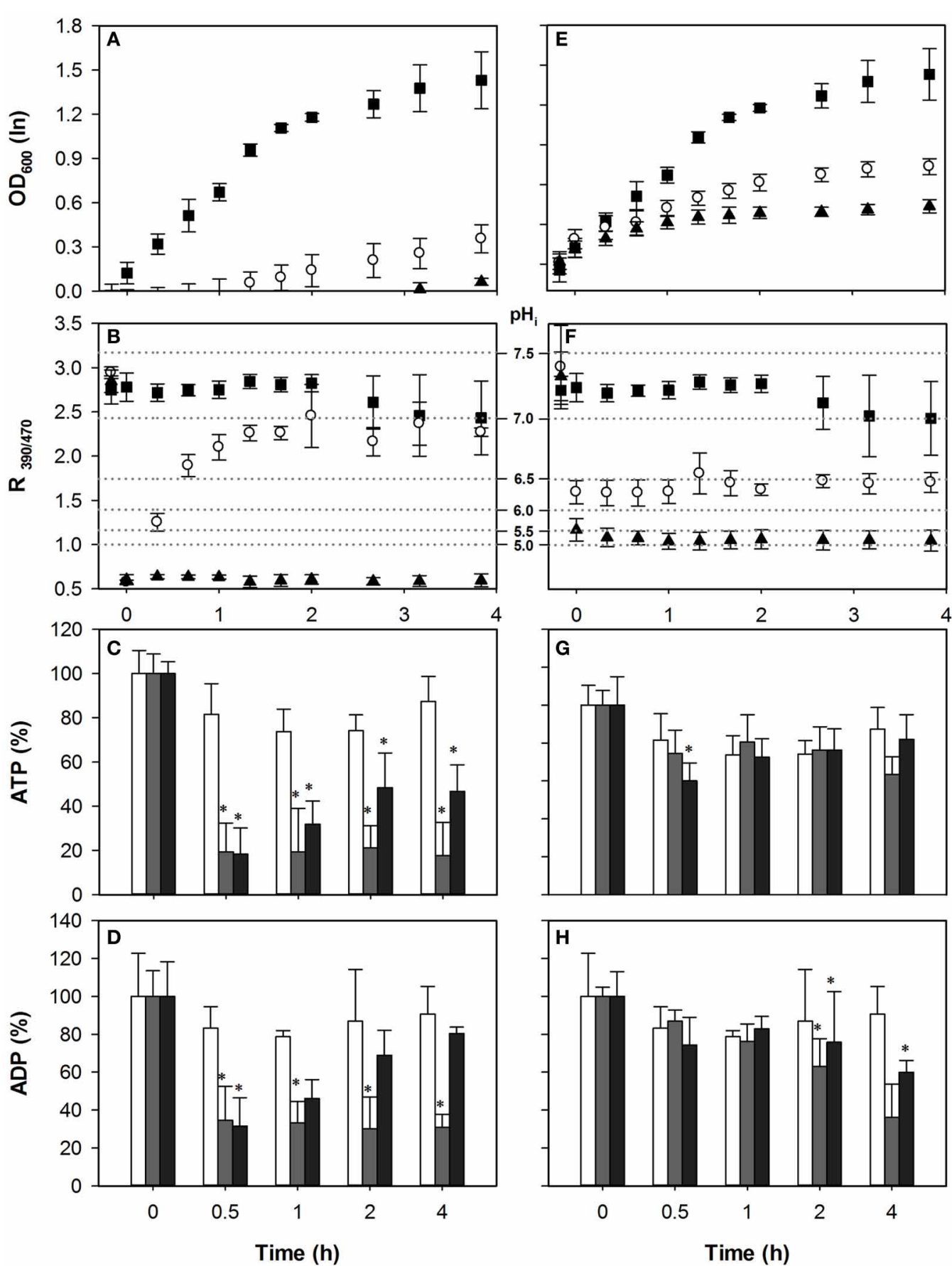

FIGURE 4 | Effect of acetic acid (left hand panels) and sorbic acid (right hand panels) on growth $(A, E)$, intracellular pH $(B, F)$, cellular ATP $(C, G)$, and ADP $(D, H)$ concentrations of pdr 12 $\Delta$. Growing cultures were exposed to $0 \mathrm{mM}$ ( $\mathbf{\square}$ and white bars), $40 \mathrm{mM} \mathrm{HA}$ or $1 \mathrm{mM} \mathrm{HS}$ (o and dark gray bars), and $70 \mathrm{mM} \mathrm{HA}$ or $2 \mathrm{mM} \mathrm{HS}$ ( $\Delta$ and black bars) at $t=0$. $\mathrm{pH}_{\mathrm{i}}$ data are presented as ratio of fluorescence emission upon excitation at $390 \mathrm{~nm}$ and $470 \mathrm{~nm}\left(\mathrm{R}_{390 / 470}\right)$ while the relevant $\mathrm{pH}_{\mathrm{i}}$ values derived from the calibration curves are also indicated. Data presented are the average of three independent cultivations and error bars represents standard deviation. An asterisk indicates significance of the difference between acid exposed and control cultures at similar time point (two-tailed $t$-test; $P<0.05$ ). activity was a major energy consuming factor upon acid stress, we would expect that deletion of PDR12 would reduce ATP consumption compared to wild type in the case of HS stress. Indeed, in contrast to the wild type cells, ATP levels were decreased only little during sorbic acid stress from $t=0.5$ to $t=4 \mathrm{~h}$ as shown in Figure 4G. The drop in the ATP was 7\% in pdr $12 \Delta$ cells with $1 \mathrm{mM}$ of sorbic acid, and $21 \%$ with $2 \mathrm{mM}$, in which case the ATP contents were mostly recovered during the 
time course (Figure 4G). No significant difference was observed in cellular ADP concentrations during the first hour of stress exposure (Figure $\mathbf{4 H}$ ).

\section{DISCUSSION}

WOAs are widely used food preservatives in food and beverage industries because they are particularly efficacious toward yeast and fungal spoilage (Winter et al., 2008). Characteristically, weakacid preservatives do not kill yeast but rather inhibit growth (Lambert and Stratford, 1999), and this ability of yeasts to survive and proliferate in the presence of WOA is an important spoilage factor. Various mechanisms are thought to contribute to the growth inhibitory effect, but quantitative mechanistic understanding is still lacking.

We showed that the adaptation to sorbic or acetic acid resulted in a decreased diffusional entry of the molecule. It has been suggested previously that adapted cells decrease the diffusional entry of acids by remodeling their plasma membranes and reinforcement of cell wall structure to decrease its porosity (Mira et al., 2010a). Furthermore, acidification is directly affected by the extent to which the cell can buffer the protons that are released. A recent study assessed the buffering capacity of living cells, and showed this to be higher than previously estimated (Maresova et al., 2010). However, this analysis of buffer capacity determined not only the passive buffering, by proton association to intracellular weak acids, but a combination of this passive buffering with active extrusion of protons to counteract the diffusional entry (Mollapour et al., 2008). To distinguish between the passive contributions of altered membrane composition and/or intracellular buffer capacity, and active proton efflux, we analyzed how the initial acidification rate depended on both of these aspects. Because the rate of acidification was not dependent on the presence of an energy source it reflects acid entry. Therefore, we concluded that pre-exposed cells indeed decrease the entry by alteration of either the structure of the plasma membrane or their cell wall composition, or by increasing intracellular buffering. Additionally, $\mathrm{pH}$ recovery depended strongly on the presence of an energy source.

\section{EFFECT OF WOA ON THE CELLULAR CONCENTRATION OF ATP}

The intracellular concentration of ATP depends on the balance between energy production and consumption. Acetic and sorbic acid are known to stimulate different response in yeast, but in both stress conditions S. cerevisiae uses energy dependent membrane transporters to expel protons and anions, which may deplete the cellular ATP pool and thus inhibit growth (Breeuwer et al., 1994; Holyoak et al., 1999; Mollapour et al., 2008). HS was previously shown not to affect ATP production (Holyoak et al., 1996). Therefore we assume that a decrease in ATP observed is due to increased consumption, likely because of the activities of Pmalp and Pdr12p, the major proton and anion exporter during HS stress in S. cerevisiae (Morsomme et al., 2000; Mollapour et al., 2008). We showed that cells do use ATP in the presence of WOA but its depletion is not a major contribution to growth inhibition in the case of acetic acid: If ATP depletion would be the major cause of growth inhibition, then reduction of ATP dependent extrusion of WOA protons and anions should increase cellular ATP, and this should then relieve the growth inhibitory effect of the WOA compared to the drop in $\mathrm{pH}$. Decreased expression of Pmalp in the pma1-007 mutant slightly reduced ATP consumption upon in response to HA exposure, but the mutant was more sensitive rather than less (Stratford et al., 2009; Ullah et al., 2012). This increased susceptibility of pma1-007 is likely due to the increased acidification rather than ATP consumption. As expected, growth, $\mathrm{pH}_{\mathrm{i}}$ and intracellular ATP levels in $p d r 12 \Delta$ cells were similar to the wild-type cells, reconfirming that Pdr12p is not instrumental in HA tolerance (Mollapour et al., 2008). ATP consumption for proton expulsion is not a major cause of growth inhibition in case of HS stress either: Reduction of ATP consumption by Pmalp indeed resulted in increased ATP concentrations, but this did not alleviate the growth inhibitory effect of the acid. Interestingly, deletion of PDR 12 also reduced ATP consumption upon sorbic acid exposure, and this now correlated with improved growth behavior [as observed before Ullah et al. (2012)]. This reconfirms that Pdr12p is active in response to HS (Holyoak et al., 1996, 1999; Piper et al., 1998), and suggests that its activity is indeed a significant ATP burden. Therefore, Pmalp and Pdr12p are active during HS stress, but neither the proton pumping nor the anion expulsion activities is truly key for adapted growth in the timeframe observed in the presence of these low dosages of sorbic acid in S. cerevisiae (Papadimitriou et al., 2007; Ullah et al., 2012). Because the growth inhibition phenotype of sorbic acid was slightly alleviated in the pdr12 $\Delta$ mutant, we conclude that the ATP consumption by Pdr12p is a larger burden to cellular functioning than is the sorbate anion accumulation.

Overall, we observed that when cells were subjected to severe WOA stress, they reduced the ATP expenditure for the recovery of either growth or $\mathrm{pH}_{\mathrm{i}}$. This suggests that yeast has evolved mechanisms that prevent WOA induced ATP depletion, since ATP levels were higher in severe stress conditions where growth was completely inhibited, compared to moderate stress where ATP levels were lower but growth was partially inhibited. This phenomenon was seen with both acetic acid, where we have shown previously that growth inhibition was mainly caused by acidification (Ullah et al., 2012), and with the more lipophilic sorbic acid, where we expected other aspects of WOA to lead to growth inhibition. This implies that cells somehow sense the severity of the stress and change the strategy of adaptation, not consuming ATP for futile attempts at recovery, but rather reserving it, in spite of the low $\mathrm{pH}_{\mathrm{i}}$ and high anion concentrations that now necessarily persist in the cell. Indeed, the $\mathrm{H}^{+}$-ATPase was shown to be inhibited by a chaperone, Hsp30p, which is induced upon stress (Piper et al., 1997). This should then be advantageous for later recovery of growth. Interestingly, we have recently shown that yeast encounters similarly low $\mathrm{pH}_{\mathrm{i}}$ values every growth cycle, since upon glucose depletion, the cytosolic $\mathrm{pH}$ eventually drops to environmental $\mathrm{pH}$ (Orij et al., 2012), without consequences for cell viability in the course of several days. Because a low $\mathrm{pH}_{\mathrm{i}}$ is a (proxy of a) signal for nutrient depletion or pending energy limitation (Dechant et al., 2010; Young et al., 2010; Orij et al., 2012), it is tempting to speculate that this signal could be used for safeguarding proper energy homeostasis or distribution upon nutrient depletion, to ensure stationary phase survival (Thomsson et al., 2005). Indeed, addition of glucose causes rapid 
phosphorylation of Pmalp, leading to its activation (Lecchi et al., 2007). This fits the notions of the interaction of nutrient sensing and growth control in response to environmental stress, where optimization of efficiency was also shown to be of key importance (Vilaprinyo et al., 2010; Zakrzewska et al., 2011). Understanding how $\mathrm{pH}_{\mathrm{i}}$ affects cellular decision making to control the biochemical activity could provide powerful tools in

\section{REFERENCES}

Ashe, M. P., De Long, S. K., and Sachs, A. B. (2000). Glucose depletion rapidly inhibits translation initiation in yeast. Mol. Biol. Cell 11, 833-848.

Bauer, B. E., Rossington, D., Mollapour, M., Mamnun, Y., Kuchler, K., and Piper, P. W. (2003). Weak organic acid stress inhibits aromatic amino acid uptake by yeast, causing a strong influence of amino acid auxotrophies on the phenotypes of membrane transporter mutants. Eur. J. Biochem. 270, 3189-3195. doi: 10.1046/j.1432-1033.2003.03701.x

Bracey, D., Holyoak, C. D., and Coote, P. J. (1998). Comparison of the inhibitory effect of sorbic acid and amphotericin B on Saccharomyces cerevisiae: is growth inhibition dependent on reduced intracellular pH? J. Appl. Microbiol. 85, 1056-1066. doi: 10.1111/j.13652672.1998.tb05271.x

Breeuwer, P., Drocourt, J. L., Rombouts, F. M., and Abee, T. (1994). Energy-dependent, carrier-mediated extrusion of carboxyfluorescein from Saccharomyces cerevisiae allows rapid assessment of cell viability by flow cytometry. Appl. Environ. Microbiol. 60, 1467-1472.

Brul, S., and Coote, P. (1999). Preservative agents in foodsmode of action and microbial resistance mechanisms. Int. J. Food Microbiol. 50, 1-17. doi: 10.1016/S0168-1605(99)00072-0

Cole, M. B., and Keenan, M. H. (1986). Synergistic effects of weak-acid preservatives and $\mathrm{pH}$ on the growth of Zygosaccharomyces bailii. Yeast 2, 93-100. doi: 10.1002/yea.320020204

Dechant, R., Binda, M., Lee, S. S., Pelet, S., Winderickx, J., and Peter, M. (2010). Cytosolic pH is a second messenger for glucose and regulates the PKA pathway through V-ATPase. EMBO J. 29, 2515-2526. doi: 10.1038/emboj.2010.138

de Kok, S., Yilmaz, D., Daran, J. M., Pronk, J. T., and van Maris, A. J. (2012). In vivo analysis of Saccharomyces cerevisiae plasma membrane ATPase
Pmalp isoforms with increased in vitro H+/ATP stoichiometry. Antonie Van Leeuwenhoek 102, 401-406. doi: 10.1007/s10482-0129730-2

Gonzalez, B., Francois, J., and Renaud, M. (1997). A rapid and reliable method for metabolite extraction in yeast using boiling buffered ethanol. Yeast 13, 1347-1355. doi: 10.1002/(SICI) 1097-0061(199711) 13:14<1347::AID-YEA176>3.0.CO; 2-O

Hatzixanthis, K., Mollapour, M. I. S., Bauer, B. E., Krapf, G., Schuller, C., Kuchler, K., et al. (2003). Moderately lipophilic carboxylate compounds are the selective inducers of the Saccharomyces cerevisiae Pdr12p ATP-binding cassette transporter. Yeast 20, 575-585. doi: 10.1002/yea.981

Henriques, M., Quintas, C., and Loureiro-Dias, M. C. (1997). Extrusion of benzoic acid in Saccharomyces cerevisiae by an energy-dependent mechanism. Microbiology 143, 1877-1883. doi: 10.1099/00221287-143-6-1877

Holyoak, C. D., Bracey, D., Piper, P. W., Kuchler, K., and Coote, P. J. (1999). The Saccharomyces cerevisiae weak-acid-inducible $\mathrm{ABC}$ transporter Pdr12 transports fluorescein and preservative anions from the cytosol by an energydependent mechanism. J. Bacteriol. 181, 4644-4652.

Holyoak, C. D., Stratford, M., McMullin, Z., Cole, M. B., Crimmins, K., Brown, A. J., et al. (1996). Activity of the plasma membrane $\mathrm{H}^{+}$-ATPase and optimal glycolytic flux are required for rapid adaptation and growth of Saccharomyces cerevisiae in the presence of the weak-acid preservative sorbic acid. Appl. Environ. Microbiol. 62, 3158-3164.

Krebs, H. A., Wiggins, D., Stubbs, M., Sols, A., and Bedoya, F. (1983). Studies on the mechanism of the antifungal action of benzoate. Biochem. J. 214, 657-663.

Lambert, R. J., and Stratford, M. (1999). Weak-acid preservatives: modelling microbial

understanding the biological mechanism of stress response and adaptation.

\section{ACKNOWLEDGMENTS}

The authors are grateful to HEC, Pakistan for financial support (Azmat Ullah). We thank many lab members for stimulating discussions and laboratory assistance.

inhibition and response. J. Appl. Microbiol. 86, 157-164. doi: 10.1046/j.1365-2672.1999.00646.x

Lecchi, S., Nelson, C. J., Allen, K. E., Swaney, D. L., Thompson, K. L., Coon, J. J., et al. (2007). Tandem phosphorylation of Ser-911 and Thr-912 at the C terminus of yeast plasma membrane $\mathrm{H}^{+}$-ATPase leads to glucosedependent activation. J. Biol. Chem. 282, 35471-35481. doi 10.1074/jbc.M706094200

Maresova, L., Hoskova, B., Urbankova, E., Chaloupka, R., and Sychrova, H. (2010). New applications of pHluorin-measuring intracellular $\mathrm{pH}$ of prototrophic yeasts and determining changes in the buffering capacity of strains with affected potassium homeostasis. Yeast 27, 317-325. doi: 10.1002/yea.1755

Mira, N. P., Palma, M., Guerreiro, J. F., and Sá-Correia, I. (2010a). Genome-wide identification of Saccharomyces cerevisiae genes required for tolerance to acetic acid. Microb. Cell Fact. 9:79. doi: 10.1186/1475-2859-9-79

Mira, N. P., Teixeira, M. C., and Sa-Correia, I. (2010b). Adaptive response and tolerance to weak acids in Saccharomyces cerevisiae: a genome-wide view. OMICS 14, 525-540. doi 10.1089/omi.2010.0072

Mollapour, M., Fong, D., Balakrishnan, K., Harris, N., Thompson, S., Schüller, C., et al. (2004). Screening the yeast deletant mutant collection for hypersensitivity and hyperresistance to sorbate, a weak organic acid food preservative. Yeast 21 , 927-946. doi: 10.1002/yea.1141

Mollapour, M., Shepherd, A., and Piper, P. W. (2008). Novel stress responses facilitate Saccharomyces cerevisiae growth in the presence of the monocarboxylate preservatives. Yeast 25, 169-177. doi: 10.1002/yea.1576

Morsomme, P., Slayman, C. W., and Goffeau, A. (2000). Mutagenic study of the structure, function and biogenesis of the yeast plasma membrane $\mathrm{H}^{+}$-ATPase. Biochim. Biophys. Acta 1469, 133-157. doi: 10.1016/S0304-4157(00)00015-0
Orij, R., Brul, S., and Smits, G. J. (2011). Intracellular $\mathrm{pH}$ is a tightly controlled signal in yeast. Biochim. Biophys. Acta 1810, 933-944. doi: 10.1016/j.bbagen.2011.03.011

Orij, R., Postmus, J., Ter Beek, A., Brul, S., and Smits, G. J. (2009). In vivo measurement of cytosolic and mitochondrial $\mathrm{pH}$ using a $\mathrm{pH}$-sensitive GFP derivative in Saccharomyces cerevisiae reveals a relation between intracellular $\mathrm{pH}$ and growth. Microbiology 155, 268-278. doi: 10.1099/mic.0.022038-0

Orij, R., Urbanus, M. L., Vizeacoumar, F. J., Giaever, G., Boone, C., Nislow, C., et al. (2012). Genome-wide analysis of intracellular $\mathrm{pH}$ reveals quantitative control of cell division rate by $\mathrm{pHc}$ in Saccharomyces cerevisiae. Genome Biol. 13:R80. doi: 10.1186/gb-2012-13-9-r80

Papadimitriou, M. N., Resende, C., Kuchler, K., and Brul, S. (2007). High Pdr12 levels in spoilage yeast (Saccharomyces cerevisiae) correlate directly with sorbic acid levels in the culture medium but are not sufficient to provide cells with acquired resistance to the food preservative. Int. J. Food Microbiol. 113, 173-179. doi: 10.1016/j.ijfoodmicro.2006.06.035

Pearce, A. K., Booth, I. R., and Brown, A. J. (2001). Genetic manipulation of 6-phosphofructo-1-kinase and fructose 2, 6-bisphosphate levels affects the extent to which benzoic acid inhibits the growth of Saccharomyces cerevisiae. Microbiology 147, 403-410.

Piper, P., Calderon, C. O., Hatzixanthis, K., and Mollapour, M. (2001). Weak acid adaptation: the stress response that confers yeasts with resistance to organic acid food preservatives. Microbiology 147, 2635-2642.

Piper, P., Mahe, Y., Thompson, S., Pandjaitan, R., Holyoak, C., Egner, R., et al. (1998). The pdr12 $\mathrm{ABC}$ transporter is required for the development of weak organic acid resistance in yeast. EMBO J. 17, 4257-4265. doi: 10.1093/emboj/17.15.4257

Piper, P. W., Ortiz-Calderon, C., Holyoak, C., Coote, P., and 
Cole, M. (1997). Hsp30, the integral plasma membrane heat shock protein of Saccharomyces cerevisiae, is a stress-inducible regulator of plasma membrane $\mathrm{H}^{+}$. ATPase. Cell Stress Chaperones 2, 12-24.

Porat, Z., Wender, N., Erez, O., and Kahana, C. (2005). Mechanism of polyamine tolerance in yeast: novel regulators and insights. Cell. Mol. Life Sci. 62, 3106-3116. doi: 10.1007/s00018-005-5341-7

Quintas, C., Leyva, J. S., Sotoca, R., Loureiro-Dias, M. C., and Peinado, J. M. (2005). A model of the specific growth rate inhibition by weak acids in yeasts based on energy requirements. Int. J. Food Microbiol. 100, 125-130. doi: $\quad 10.1016 / j . i j f o o d m i c r o .2004$. 10.009

Schüller, C., Mamnun, Y. M., Mollapour, M., Krapf, G., Schuster, M., Bauer, B. E., et al. (2004). Global phenotypic analysis and transcriptional profiling defines the weak acid stress response regulon in Saccharomyces cerevisiae. Mol. Biol. Cell 15, 706-720. doi: 10.1091/mbc.E03-05-0322

Serrano, R., Kiellandbrandt, M. C., and Fink, G. R. (1986). Yeast plasma-membrane ATPase is essential for growth and has homology with $\left(\mathrm{Na}^{+}+\mathrm{K}^{+}\right), \mathrm{K}^{+}$- and $\mathrm{Ca}-2^{+}$. Atpases. Nature 319, 689-693. doi: 10.1038/319689a0

Stratford, M., Plumridge, A., NebeVon-Caron, G., and Archer, D. B. (2009). Inhibition of spoilage mould conidia by acetic acid and sorbic acid involves different modes of action, requiring modification of the classical weak-acid theory. Int. J. Food Microbiol. 136, 37-43. doi: 10.1016/j.ijfoodmicro.2009.09.025

Thomsson, E., Svensson, M., and Larsson, C. (2005). Rapamycin pretreatment preserves viability, ATP level and catabolic capacity during carbon starvation of Saccharomyces cerevisiae. Yeast 22, 615-623. doi: 10.1002/yea.1219

Ullah, A., Orij, R., Brul, S., and Smits, G. J. (2012). Quantitative analysis of the modes of growth inhibition by weak organic acids in Saccharomyces cerevisiae. Appl. Environ. Microbiol. 78, 8377-8387. doi: 10.1128/AEM.02126-12

Verduyn, C., Postma, E., Scheffers, W. A., and Vandijken, J. P. (1992). Effect of benzoic-acid on metabolic fluxes in yeasts-a continuousculture study on the regulation of respiration and alcoholic fermentation. Yeast 8, 501-517. doi: 10.1002/yea.320080703

Vilaprinyo, E., Alves, R., and Sorribas, A. (2010). Minimization of biosynthetic costs in adaptive gene expression responses of yeast to environmental changes. PLoS Comput. Biol. 6:e1000674. doi: 10.1371/journal.pcbi.1000674

Winter, G., Hazan, R., Bakalinsky, A. T., and Abeliovich, H. (2008) Caffeine induces macroautophagy and confers a cytocidal effect on food spoilage yeast in combination with benzoic acid. Autophagy 4 , 28-36.

Young, B. P., Shin, J. J., Orij, R. Chao, J. T., Li, S. C., Guan, X. L., et al. (2010). Phosphatidic acid is a $\mathrm{pH}$ biosensor that links membrane biogenesis to metabolism. Science 329, 1085-1088. doi: 10.1126/science.1191026

Zakrzewska, A., van Eikenhorst, G., Burggraaff, J. E., Vis, D. J., Hoefsloot, H., Delneri, D., et al. (2011). Genome-wide analysis of yeast stress survival and tolerance acquisition to analyze the central trade-off between growth rate and cellular robustness. Mol. Biol. Cell 22,
4435-4446. doi: 10.1091/mbc.E1008-0721

Conflict of Interest Statement: The authors declare that the research was conducted in the absence of any commercial or financial relationships that could be construed as a potential conflict of interest.

Received: 24 December 2012; accepted: 20 May 2013; published online: 11 June 2013.

Citation: Ullah A, Chandrasekaran G, Brul S and Smits GJ (2013) Yeast adaptation to weak acids prevents futile energy expenditure. Front. Microbiol. 4:142. doi: 10.3389/fmicb.2013.00142

This article was submitted to Frontiers in Microbial Physiology and Metabolism, a specialty of Frontiers in Microbiology.

Copyright (C) 2013 Ullah, Chandrasekaran, Brul and Smits. This is an open-access article distributed under the terms of the Creative Commons Attribution License, which permits use, distribution and reproduction in other forums, provided the original authors and source are credited and subject to any copyright notices concerning any third-party graphics etc. 